\title{
An investigation of Mechanical characterization of Orange Peel Reinforced Epoxy Composite
}

\author{
Katla.Praveen Kumar ${ }^{1}$, Chetty.Nagaraj ${ }^{2}$ \\ ${ }^{1}$ Assistant Professor, Department, of mechanical Engineering, St .Peter's Engineering College, Maisammaguda \\ (V), Medchal (M).Hyderabad.500014, Telengana, India. \\ ${ }^{2}$ Assistant Professor, Department, of mechanical Engineering, CMR Technical Campus Kandlakoya(V), \\ Medchal (M), Hyderabad- 501401, Telengana, India.
}

\begin{abstract}
Polymeric materials reinforced with synthetic fibers such as glass, carbon, and aramid provide advantages of high stiffness and strength to weight ratio as compared to conventional construction materials, i.e. Wood, concrete and steel. Despite these advantages, the widespread use of synthetic fiber-reinforced polymer composite has a tendency to decline because of their high-initial costs, their use in non-efficient structural forms and most importantly their adverse environmental impact. However, natural filler and fiber materials are emerging as suitable alternatives to synthetic materials for reinforcing polymers such as epoxy due to their environment friendliness, high abundance, renewability, and cost effectiveness. Several research efforts have been put to study the effectiveness of natural fiber based materials on the mechanical behaviour of epoxy composites, focusing mainly on fibers and their weight percent's within the composites. The present experimental study aims at learning Mechanical behaviour of orange peel reinforced epoxy composites and effect of the weight percentage of the orange peel reinforcement was investigated experimentally on the mechanical properties of the developed composites. The mechanical properties were tested using computerized UTM machine as per the ASTM standards. Its biodegradability, low cost, and moderate mechanical properties make it a preferable reinforcement material in the development of polymer matrix composites. Composites having 5, 10, 20 and 30\% weight fraction of orange peel specimens were made by using hand layup method. The fabricated composite samples were cut according to the ASTM standards for different experiments. density test, Hardness test were carried out at the samples. The maximum hardness, density, tensile, flexural and ILSS are getting for the material prepared with the $20 \%$ reinforced orange peel epoxy composite.
\end{abstract}

Keywords: Composites, density, Hardness, Mechanical Strength, orange peel.

\section{Introduction}

When two or more material with different properties is combined together they form a composite material [1]. The composite materials have a higher strength than many other materials. Normally the good quality fibers having highest cost,Synthetic fibers are non renewable fiber and the availability of the fiber was also difficult. The constituents are combined in such a way that they keep their individual physical phases and are non soluble in each other or do not form a new chemical compound. There are basically two category of constituent material, one constituent is called reinforcing phase and one in which the reinforcing phase is embedded is called matrix. The primary function of matrix is to hold the fiber to form a certain shape. Besides, the functions of the matrix are also to transfer stress between the reinforcing fibers and to protect them from mechanical and environmental damage. The function of reinforcing phase in matrix is to improve the mechanical properties such as strength, stiffness etc. As per Berghezan [2] the composite material is to be designed in such a way that the individual component retain their characteristic are so incorporated that the composite take advantage of their superior properties without compromising on the weakness of either.

Among all reinforcing fibres, natural fibres have gained great significance as reinforcements in polymer matrix composites. Depending upon the source of origin, natural fibres are classified as plant, animal and mineral fibres. Recently, due to the growing global energy crisis and ecological risks, natural fibres reinforced polymer composites have attracted more research interests. The main advantages of natural fibres are their availability, biodegradable, renewable, environmental friendly, low cost, low density, high specific properties,good thermal properties and enhanced the energy recovery, low energy consumption, non-abrasive nature and low cost. Plant fibres are justifies their use as reinforcement for polymer composites due to their renewability with good mechanical properties. It is also observed that natural fibres are non-uniform with irregular cross sections, which make their structures quite unique and much different from man-made fibres such as glass fibres, carbon fibres etc. As far as reinforcement is concerned fibers occupy the largest weight fraction in a FRP composite and it share its major portion of the load that act on the composite structure. The 
reinforcing fibers can be oriented during fabrication there by giving ample opportunity to the designer to tailor down the properties in specific direction.

\subsection{Objectives}

The objectives of the present work are:

- To prepare the orange peel particulates of desired particle size.

- To fabricate the particulate with different weight percentage in the epoxy matrix.

- To study the density of different samples.

- To check the micro-hardness of different samples.

- To perform the tensile and flexural tests on the composite samples.

- To conduct the SEM for the tensile and flexural tested samples to study the nature of failure at the microscopic level.

\subsection{Materials}

\section{Methodology}

Raw materials used in this experimental work are listed below

1. Natural fiber (Orange peel)

2. Epoxy Resin

3. Hardener

Orange peel: Orange is a citrus fruit mainly originated in Southeast Asia. It is the most commonly grown tree fruit in the world. Like all citrus fruits, the orange is acidic having $\mathrm{pH}$ range 2.9-4.0.

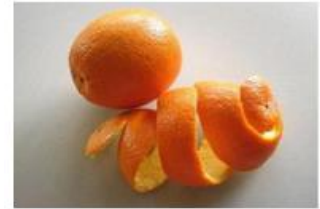

Figure 2.1 (a) Orange peels

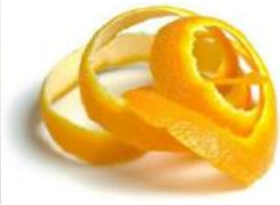

bun dried orange peel

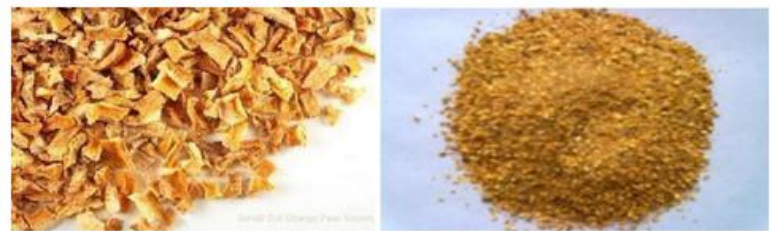

(c) Powdered orange peels

Orange peel, the outer cover part of an orange, mainly consists of cellulose, essential oils, proteins and some simple carbohydrates. The orange peels were collected locally and were sun dried for 5 days. Sun drying was necessary to remove the moisture from the peels. The fibers were then grinded into fine powder as shown in figure 2 .

The collected powders were sieved and a particle size distribution in a sample is given in Table-2.1. Since the wt $\%$ of $212+$ microns was around 74.6grams, for the present investigation we have taken this particle size for further experimentation.

\begin{tabular}{|c|c|c|c|c|}
\hline $\begin{array}{c}\text { sample } \\
\text { No }\end{array}$ & $\begin{array}{c}\text { size in } \\
\text { micron }\end{array}$ & $\begin{array}{c}\text { Sample size } \\
\text { +micron }\end{array}$ & $\begin{array}{c}\text { appro.wt. } \\
\text { in.grams }\end{array}$ & weight\% \\
\hline 1 & --- & 1700 & 22.25 & 18.12 \\
\hline 2 & ---- & 212 & 74.6 & 67.16 \\
\hline 3 & 212 & 150 & 4.87 & 4.38 \\
\hline 4 & 150 & 106 & 4.17 & 3.75 \\
\hline 5 & 106 & --- & 5.18 & 4.66 \\
\hline & & Total & 111.07 & \\
\hline
\end{tabular}

Table 2.1 Particles Size

\subsection{Epoxy Resin}

The type of epoxy resin used in the present investigation is araldite LY556 which is chemically belongs to epoxide family. Its common name is BisPhinol-A-Diglycidyl-Ether. It is supplied by CIBA GUGYE India Limited.

\subsection{Hardener}

The hardener with IUPAC name NNO-bis (2aminoethylethane-1,2diamin) has been used with epoxy designated as HY951. This has a viscosity of $10-20 \mathrm{M} \mathrm{Pa}$ at $25^{\circ} \mathrm{C}$. 


\subsection{Composite preparation}

A Per-pex sheet mould (dimension 130x100x6 mm) figure-2.2 has used for casting the composite sheet. A mould release spray was applied at the inner surface of the mould for quick and easy release of the composite sheet. A calculated amount of epoxy resin and hardener (ratio of 10:1 by weight) was taken and mixed with orange peel particulate with gentle stirring to minimize air entrapment. After keeping the mould on a glass sheet (coated with wax) the mixture is then poured into it. Care was taken to avoid formation of air bubbles. Pressure applied from the top, and the mould was allowed to cure at room temperature for $72 \mathrm{hrs}$. During application of pressure some amount of epoxy and hardener squeezes out. Care has been taken to consider this loss during manufacturing so that a constant thickness of sample could be manufactured. This procedure was adopted for preparation of 5, 10, 20 and 30\% weight fractions of orange peel. After $72 \mathrm{hrs}$ the samples were taken out of the mould, cut into different sizes and kept in air tight container for further experimentation.

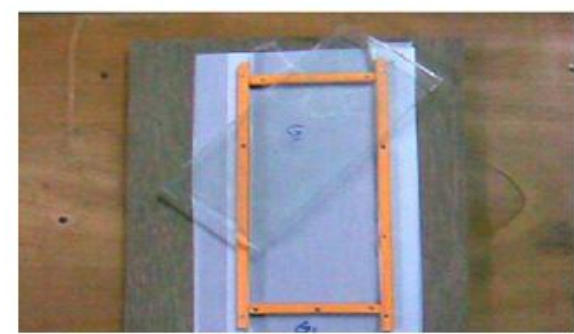

Figure 2.2 (a) Mould

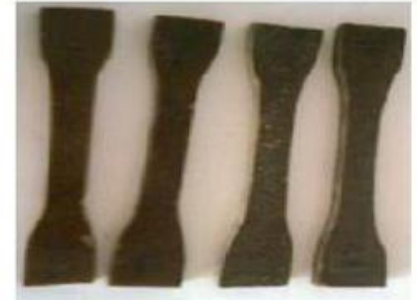

(b) Tensile test specimen

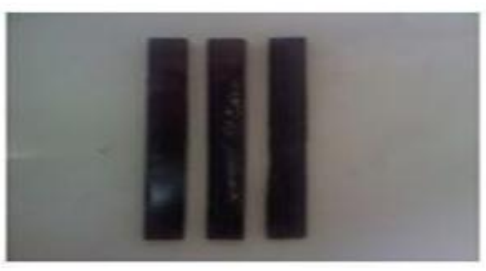

(c) Flexural test specimen

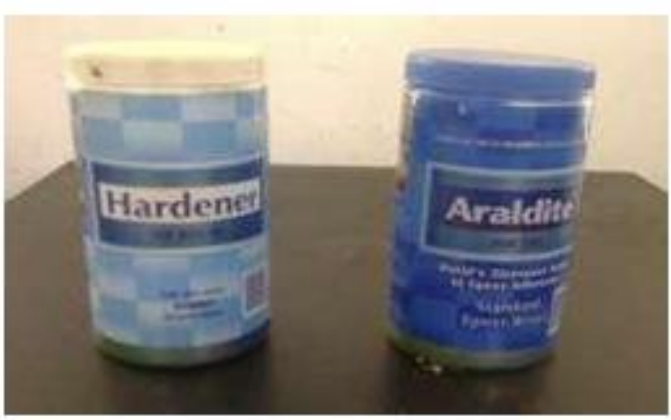

(d) Hardener and Araldite (Epoxy resin)

\section{Testing of Mechanical Properties}

After fabrication, the test specimens were subjected to various Mechanical testing as per ASTM standards. The mechanical tests that carried out Density measurement Hardness test, Tensile test, Flexural test. The entire specimens were of rectangular cross section of size 150x20x5 mm.

\section{Density Measurement}

The density of composite materials in terms of volume fraction is found out from the following equations

$$
\mathrm{s}_{\mathrm{ct}}=\frac{\mathrm{w}_{0}}{\left(\begin{array}{lr}
\mathrm{w} & )+(\mathrm{w}-w) \\
0 & \mathrm{a} \quad b
\end{array}\right.}
$$

Where $\rho_{\mathrm{ct}}{ }^{\text {ee }}$ represents specific gravity of the composite,

$\mathrm{W}_{0}$ represents the weight of the sample; $\mathrm{W}_{\mathrm{a}}$ represents the weight of the bottle + kerosene,

$\mathrm{W}_{\mathrm{b}}$ represents the weight of the bottle + kerosene + sample,

$$
\text { Density of composite }=S_{c t} \text { * density of kerosene. }
$$

The theoretical density of composite materials in terms of weight fraction is found out from the following equations as given by Agarwal and Broutman [3]. 
1

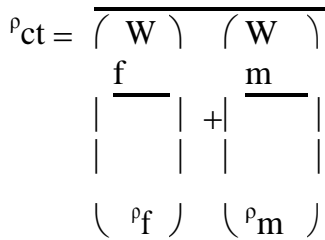

Where,$W^{\prime}$ and,$\rho^{\text {ee }}$ represents the weight and density respectively. The suffix $f, m$ and $c t$ stand for the fiber, matrix and the composite materials.

The void content of composite sample has been determined as per ASTM D-2734-70 standard procedure respectively. The volume fraction of voids $\left(\mathrm{V}_{\mathrm{v}}\right)$ in the composites was calculated by using equation: where $\boldsymbol{\rho}_{t}$ and $\boldsymbol{\rho}_{\boldsymbol{a}}$ are the theoretical and actual density of composite respectively

$$
V_{v}=\frac{\rho t-\rho_{a}}{\rho_{\mathrm{t}}}
$$

\section{Hardness Test}

Leitz Micro -hardness tester was used for Hardness measurement. This tester had a diamond indentater, in the form a right pyramid with a square base and an angle $136^{\circ}$ between opposite faces, is forced in to the material under a load ranging from 0.3 to $3 \mathrm{~N}$. Vickers hardness number is calculated by using the following equations.

$$
\begin{aligned}
& \mathrm{L}=(\mathrm{X}+\mathrm{Y}) / 2 \\
& \mathrm{Hv}=0.1889 \mathrm{~F} / \mathrm{L}^{2}
\end{aligned}
$$

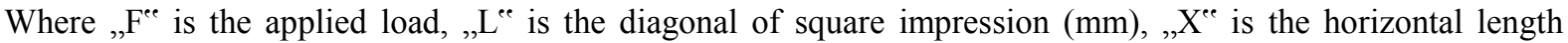
$(\mathrm{mm})$, and , $\mathrm{Y}^{\mathrm{ec}}$ is the vertical length $(\mathrm{mm})$.

\section{Tensile Test}

The tension test is generally performed on flat specimens. The most commonly used specimen geometries are the dog-bone specimen, figure-3.1, and straight-sided specimen with end tabs. The standard test method as per ASTM D3039-76 has been used. The length of the test specimen used is $150 \mathrm{~mm}$. The tensile test is performed in universal testing machine (UTM). The tests were performed with a cross head speed of $0.5 \mathrm{~mm} / \mathrm{min}$. For each test composite of four samples were tested and average value was taken for analysis. Figure 3.2(a, b) shows the machine used for the test and the sample in loading condition.

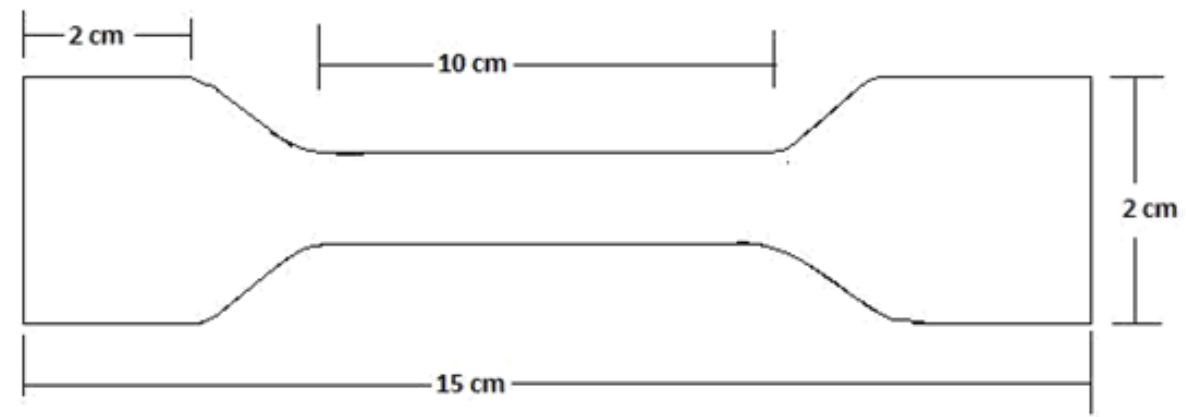

Figure- 3.1 Dog bone shape of the tensile testing sample 


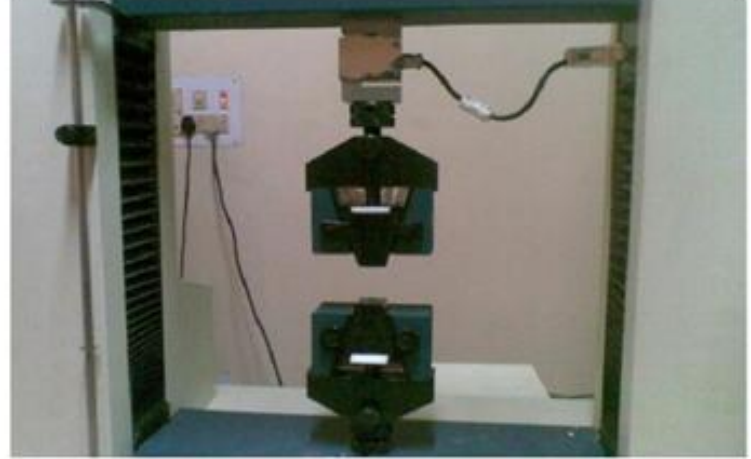

Figure 3.2 (a) UTM Machine Sample holde

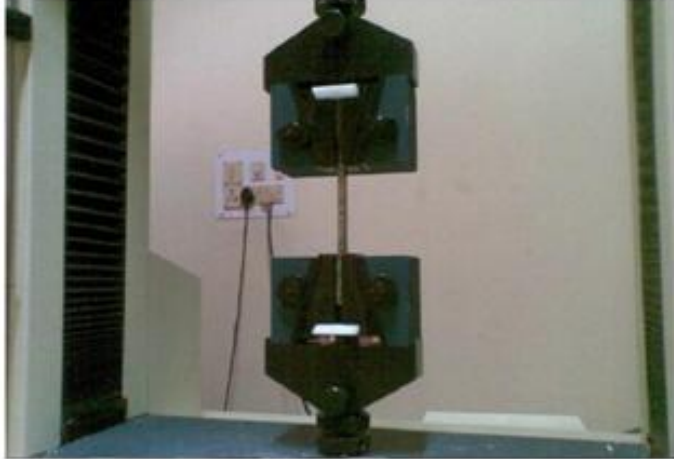

(b) UTM Machine Sample Loaded

\section{Flexural Strength}

The three point bend test was carried out in UTM machine in accordance with ASTM D2344-84 to measure the flexural strength of the composites. The loading arrangement for the specimen and the photograph of the machine used are shown in Figure-3.3(a) and (b) respectively. The entire specimens were of rectangular cross section of $(150 \times 20 \times 5) \mathrm{mm}$. A span of $100 \mathrm{~mm}$ was used for the test specimen. The specimens were tested at a crosshead speed of $0.5 \mathrm{~mm} / \mathrm{min}$. The flexural stress in a three point bending test is found out by using equation (3.6)

$$
\sigma=\frac{3 F L}{2 b t^{2}}
$$

Where $\mathrm{F}$ is the load, $\mathrm{b}$ is the width and $\mathrm{t}$ is the thickness of the specimen under test.

The short beam shear tests (SBS) are performed on the composite samples at room temperature to evaluate the value of inter-laminar shear strength (ILSS). It is three point bending test which generally promotes failure by inter-laminar shear. The SBS test is conducted as per ASTM standard using the same UTM, span length $100 \mathrm{~mm}$ and cross head speed $0.5 \mathrm{~mm} / \mathrm{min}$.

The inter-laminar shear strength (ILSS) is found out by using the equation (3.7)

$$
\mathrm{ILSS}=\frac{3 F}{4 b . t}
$$

Where $\mathrm{F}$ is the maximum load, $\mathrm{b}$ the width of the specimen and $\mathrm{t}$ is the thickness of the specimen.

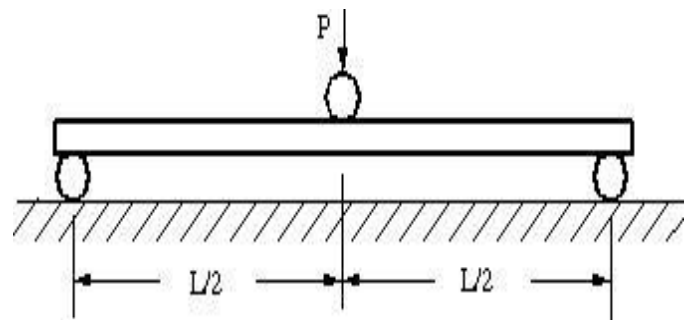

Figure 3.3(a) the loading arrangement for the flexural testing

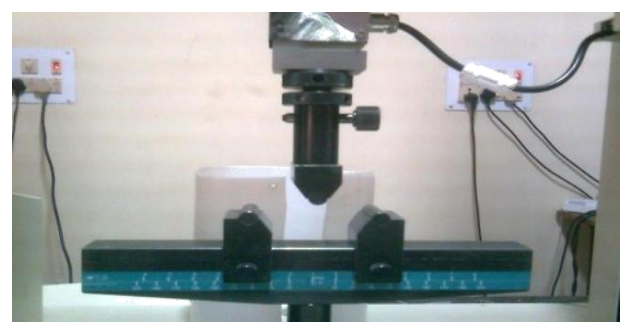

Figure 3.3 (b) Flexural specimen loading position

\section{Density Measurement}

\section{Results And Discussion}

From the table 4.1 it is observed that the void fraction percentage of composite increases as the percentage of reinforcement increases still the void content is very less so it shows that the composite fabrication is done properly.

Figure 4.1 is drawn between the measured densities of the composites and weight fraction of the composite. It is observed that as the reinforcement percentage increases in the epoxy the density increases gradually up to $20 \%$ and suddenly decreases at $30 \%$ due to void percentage increases the void content increase 
due to the weight percentage of fiber increases.

Table 4.1 Density of different Samples

\begin{tabular}{|c|c|c|c|}
\hline $\begin{array}{c}\text { Fiber content } \\
(\%)\end{array}$ & Measured & Theoretical & $\begin{array}{c}\text { Volume fraction } \\
\text { of voids }(\%)\end{array}$ \\
\cline { 2 - 3 } & $\begin{array}{c}\text { Density } \\
\left(\mathrm{gm} / \mathrm{cm}^{3}\right)\end{array}$ & $\begin{array}{c}\text { Density } \\
\left(\mathrm{gm} / \mathrm{cm}^{3}\right)\end{array}$ & \\
\hline 0 & 1.082 & 1.100 & 1.636 \\
\hline 5 & 1.0991 & 1.118918 & 1.7712 \\
\hline 10 & 1.113 & 1.138498 & 2.239613 \\
\hline 20 & 1.143 & 1.179788 & 3.118215 \\
\hline 30 & 1.1398 & 1.224186 & 6.893266 \\
\hline
\end{tabular}

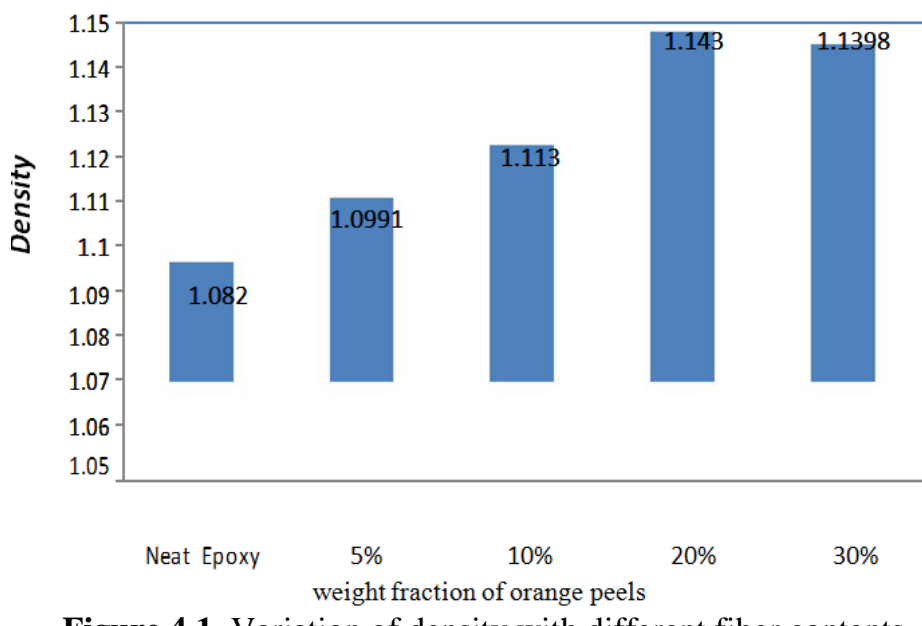

Figure 4.1. Variation of density with different fiber contents

\section{Hardness Test}

Vickers hardness number is measured by Leitz Micro -hardness tester. The results are tabulated in the table 4.2. Figure 4.2 drawn between the harness values of composite and the weight percentage of composite. It is observed that as the reinforcement increases the hardness increases the maximum value is obtained for composite prepared with the $20 \%$ composite.

Table 4.2 Hardness of different samples

\begin{tabular}{|c|c|}
\hline $\begin{array}{c}\text { Weight fraction of } \\
\text { particulates } \\
(\boldsymbol{\%})\end{array}$ & Vicker Hardness value \\
\hline Neat epoxy & 17.894 \\
\hline 5 & 18.28 \\
\hline 10 & 19.68 \\
\hline 20 & 20.72 \\
\hline 30 & 18.95 \\
\hline
\end{tabular}

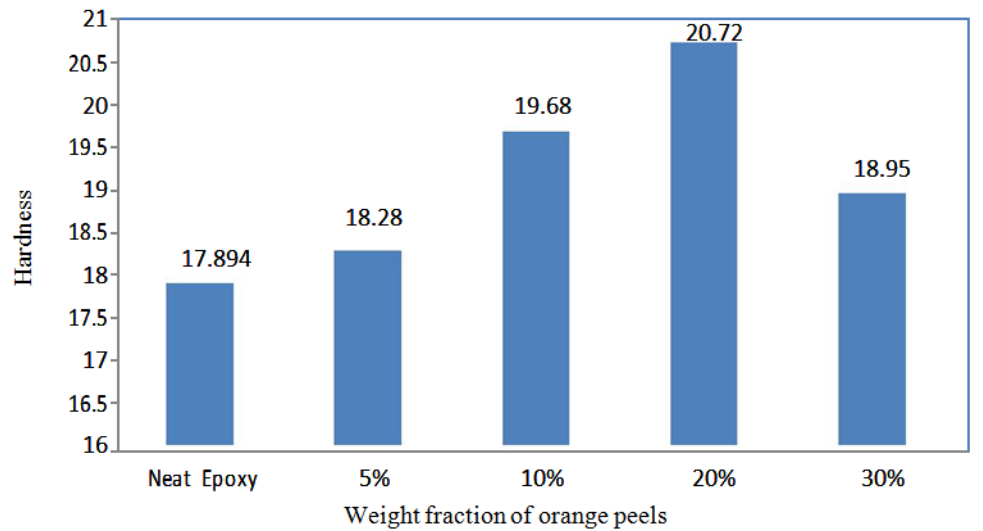

Figure 4.2 Variation of Vicker Hardness value with different fiber contents 


\section{Tensile Test}

The results of tensile test using UTM are tabulated in Table 4.3. From figure 4.3 it is observed that the tensile strength is maximum for the composite prepared with $20 \%$ fiber However, for $30 \%$ fiber composite the tensile strength decreases because of the void content.

\begin{tabular}{|c|c|c|}
\hline $\begin{array}{c}\text { Weight percent } \\
\text { of fiber }\end{array}$ & $\begin{array}{l}\text { Tensile Stress } \\
\text { (MPa) }\end{array}$ & $\begin{array}{l}\text { Tensile Modulus } \\
\text { (MPa) }\end{array}$ \\
\hline Neat epoxy & 18.031 & 648.23 \\
\hline $5 \%$ & 19.25 & 742.46 \\
\hline $10 \%$ & 22.69 & 1313.63 \\
\hline $20 \%$ & 25.85 & 1271.69 \\
\hline $30 \%$ & 21.34 & 938.96 \\
\hline
\end{tabular}

Table 4.3 Tensile Stress and Tensile Modulus of composites

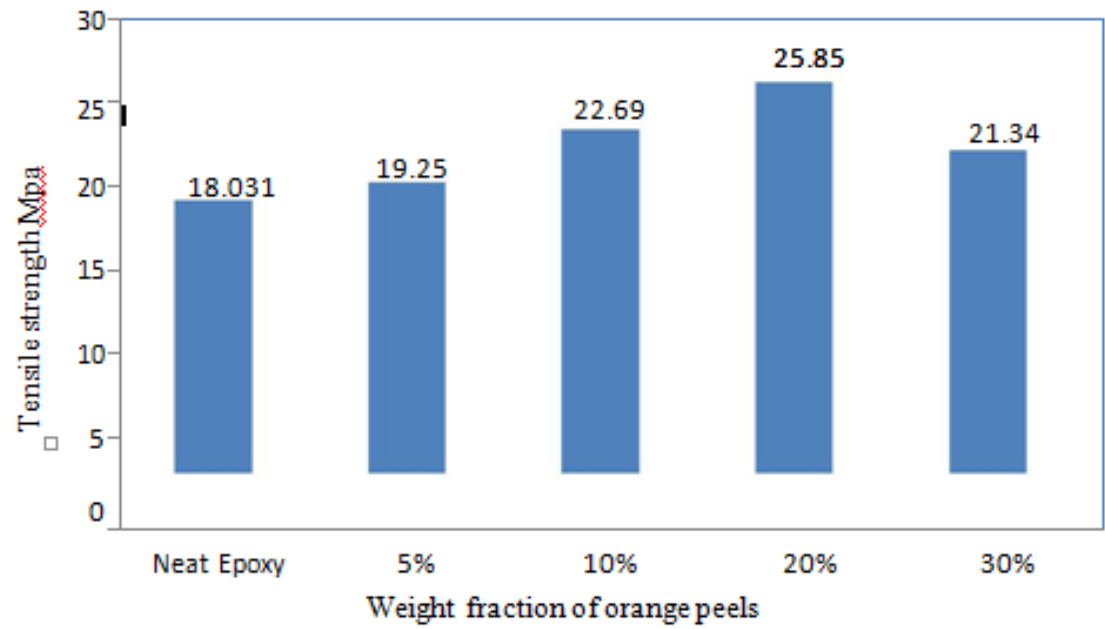

Figure 4.3 Variation of Tensile strength with different fiber contents

\section{Flexural Test}

The three point bend test was carried out in UTM 201 machine in accordance with ASTM D2344-84 to measure the flexural strength of the composites. The flexural strength, flexural modulus and ILSS values are tabulated in Table 4.4. From the table, it is observed that the composite having $20 \%$ fiber content has the highest values of flexural strength, flexural modulus and ILSS. Figures 4.4 and 4.5 it is observed that the flexural and ILSS values are getting maximum for the composite prepared with $20 \%$ fiber.

\begin{tabular}{|c|c|c|c|}
\hline $\begin{array}{c}\text { Weight fraction } \\
\text { of } \\
\text { particulates(\%) }\end{array}$ & $\begin{array}{c}\text { Flexural } \\
\text { Strength(MPa) }\end{array}$ & $\begin{array}{c}\text { Flexural } \\
\text { modulus(GPa) }\end{array}$ & LSS \\
\hline Neat epoxy & 45.519 & 5.046 & 1.137 \\
\hline $5 \%$ & 48.23 & 5.146 & 1.425 \\
\hline $10 \%$ & 56.98 & 9.631 & 1.653 \\
\hline $20 \%$ & 62.35 & 10.970 & 1.808 \\
\hline $30 \%$ & 57.89 & 8.334 & 1.765 \\
\hline
\end{tabular}

Table 4.4 Flexural properties of the composites 


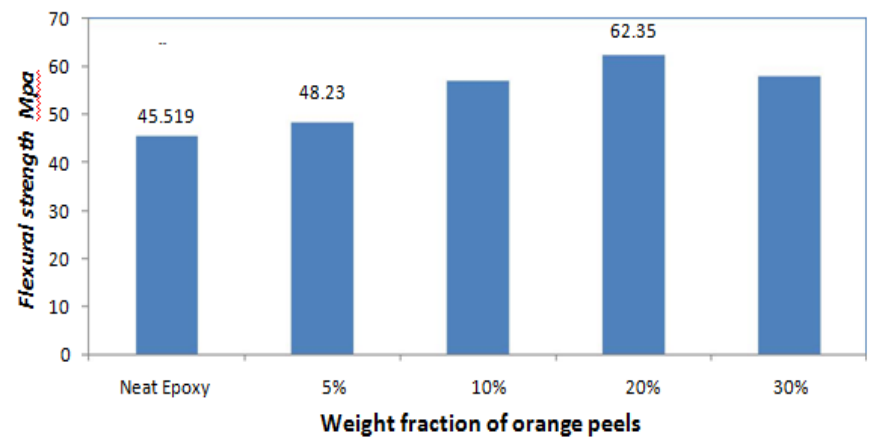

Figure 4.4 Variation of flexural strength with different fiber contents

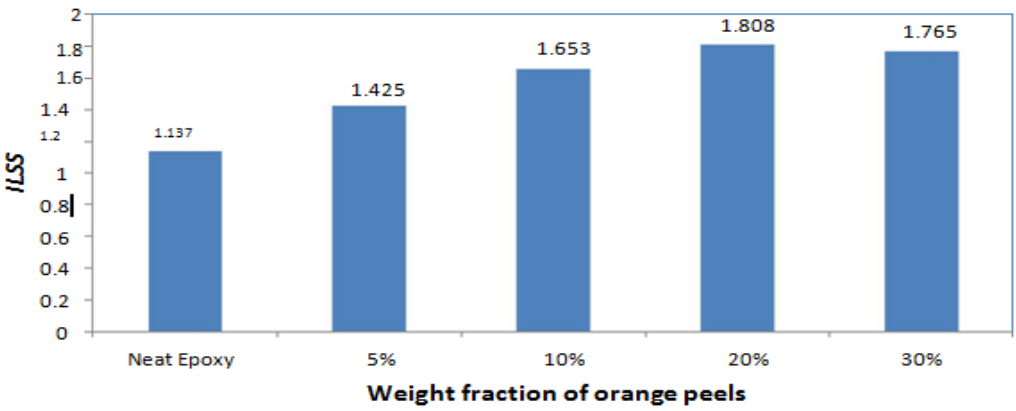

Figure 4.5 Variation of ILSS with different fiber contents

\section{SEM Analysis}

Scanning electron micrographs (SEM) of resin sample and its respective composites were taken on Leo 435 VP. Figure 4.6 is the micro graphs of the $20 \%$ orange peel reinforced epoxy composite which is subjected to tensile test. Micrographs clearly show that no debonding, no fiber chipping out and no crack formation it shows that the bonding is strong between the matrix and reinforcement.

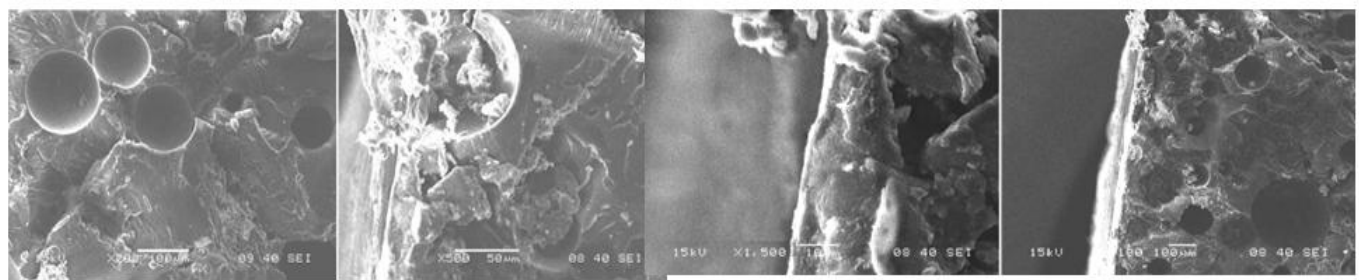

Figure 4.6 SEM micrograph of $20 \%$ orange peel composite after tensile test
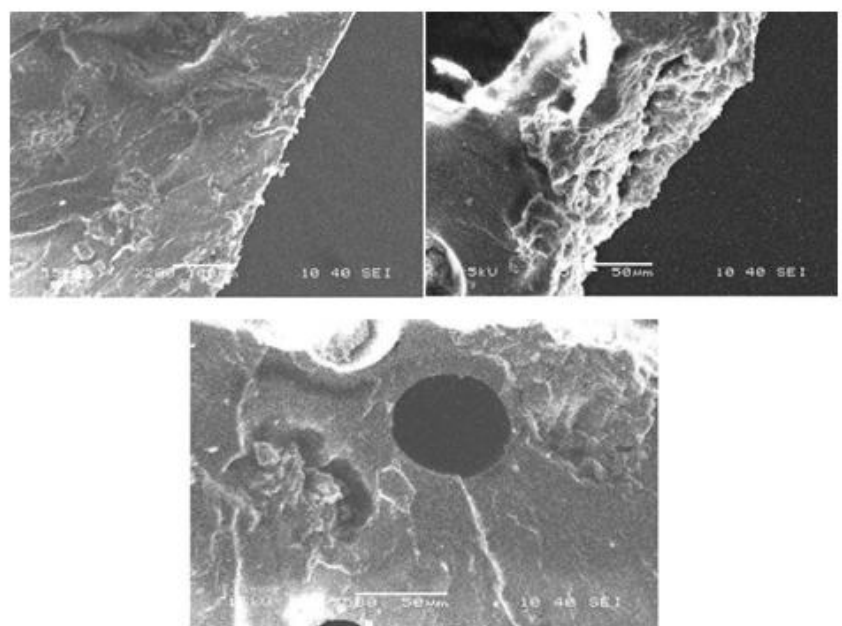

Figure 4.7 SEM micrograph of 20\% orange peel composite after flexural test 
Figure 4.7 is the micro graphs of the $20 \%$ orange peel reinforced epoxy composite which is subjected to flexural strength micrographs clearly show that some bending of fibers are taken place but the fibers are not come out from the epoxy it shows that the bonding is more between the epoxy and orange peel fiber.

\section{Conclusions}

The present work deals with the preparation of characterization of waste orange fiber reinforced epoxy composite. The mechanical behavior of the composite lead to the following conclusions

1. With the successful fabrication of a new class of epoxy based composites reinforced with orange fiber.

2. The flexural strength and ILSS of the composite is found to be maximum with $20 \%$ weight percent of orange fiber.

3. The tensile strength of the composite is found to be maximum for the $20 \%$ weight percentage of the orange fiber.

4. The hardness value of the composite increases with increasing of the fiber content.

5. SEM observation reveals that most of the fibers were broken instead of pulling out from the matrix. This indicates a good bonding between fiber and the matrix.

\section{References}

[1]. Herakovich, C.T., "Mechanics of fibrous composites". New York: Wiley; (1998). p. 1- 27 .

[2]. Berghezan, A.," Nucleus", 8(5), 1966, (Nucleus an Editeur, 1, rhe, Chalgrin, Paris,) 16(e).

[3]. Agarwal B.D., and Broutman L.J., "Analysis and performance of fiber composites" John Wiley \& Sons, NewYork, (1980): p. 3-12.

[4]. Mallick P.K. 1993. Fiber Reinforced Composite: Materials, Manufacturing And Design, Second Edition, 18 , Marcel Dekker Inc, Newyork,

[5]. Abdul Khalil M., Abu Bakar A., Mariatti M., Jannah, H. P. S. 2008. Properties of Banana and Pandanus Woven Fabric Reinforced Unsaturated, Polyester Composites, Journal of Composite Materials, 42 (9), pp.931-941

[6]. Santos C.J.E. 2009. Development of Fiber Reinforced Composite for Structural Applications, Submitted in partial fulfillment of course requirements for MatE 198B.

[7]. Rong, M.Z., Zhang, M.Q., Liu, Y., Yang, G.C. and Zeng, H.M., 2001, "The effect of fiber treatment on the mechanical properties of unidirectional sisal-reinforced epoxy composites," Compos. Sci. Technol., 61; pp. 14371447.

[8]. Wambua P., Ivens J, Verpoest I., 2003, "Natural fibers: can they replace glass in fiber reinforced plastics, Compos Science Technology"; 63: 1259-64.

[9]. Schuh TG., "Renewable materials for automotive applications". Http // www. Ienica. net / fibers seminar/schuh.pdf (Accessed in February 2006).

[10]. Khedari J., Charoemvai S., Hiruanlabh J., "New insulating particle boards from durian peel and coconut coir. Build Environ"; 38: 2003, 435-441.

[11]. Bledzki A K., Gassan J., "Composites reinforced with cellulose based fibres". Progress in Polymer Science, Volume 24, (1999): p. 221-274.

[12]. Frank, R.R.," Bast and other plant fibers", 2005. Cambridge: woodhead publishing limited.

[13]. Z. Zhikai, Z. Sixun, H. Jinyu C. Xingguo, G. Qipeng, and W. Jun, Phase Behavior and Mechanical Properties of Epoxy Resin Containing Phenolphthalein Poly ether ether Ketone, Journal of Polymer, 39 (5), (1997), pp. 10751080.

[14]. H. Shangjin, S. Keyu, B. Jie, Z. Zengkun, L. Liang, D. Zongjie and Z. Baolong, "Studies on the Properties of Epoxy Resins Modified with Chain-Extended Ureas", Journal of Polymer, 42 (2001), pp. 9641-9647.

[15]. R. S. Bauer (ed.), "Epoxy Resin Chemistry II", ACS Symposium Series, no. 201. Washington, DC: American Chemical Society, 1983.

[16]. R. S. Drake, D. R. Egan, and W. T. Murphy in "Epoxy Resin Chemistry II", (ed. R. S. Bauer), ACS Symposium Series no. 221. Washington, DC: American Chemical Society, 1982, p. 1.

[17]. J. S. Riffle, I. Yilgor, A. K. Banthia, C. Tran, G. L. Wilkes, and J. E. McGrath in "Epoxy resin chemistry", (ed. R. S. Bauer), ACS Symposium Series no. 201. Washington, DC: American Chemical Society, 1983, p. 21.

[18]. Van Paepegem, W. and Degrieck, J. (2001). "Modelling Strategies for Fatigue Damage Behaviour of Fibrereinforced Composites. European Journal of Mechanical and Environmental Engineering, 46(4), 217-227.

[19]. Van Paepegem, W. and Degrieck, J. (2001). "Experimental set up for numerical modelling of bending fatigue experiments on plain woven glass/epoxy composites, composite structures 51(1), 1-8. 